\title{
Relevance of Simpson grading system and recurrence-free survival after surgery for World Health Organization Grade I meningioma
}

\author{
Anil Nanda, MD, MPH, Shyamal C. Bir, MD, PhD, Tanmoy K. Maiti, MCh, Subhas K. Konar, MCh, \\ Symeon Missios, MD, and Bharat Guthikonda, MD \\ Department of Neurosurgery, LSU Health Shreveport, Louisiana
}

OBJECTIVE The clinical significance of the Simpson system for grading the extent of meningioma resection and its role as a predictor of the recurrence of World Health Organization (WHO) Grade I meningiomas have been questioned in the past, echoing changes in meningioma surgery over the years. The authors reviewed their experience in resecting WHO Grade I meningiomas and assessed the association between extent of resection, as evaluated using the Simpson classification, and recurrence-free survival (RFS) of patients after meningioma surgery.

METHODS Clinical and radiological information for patients with WHO Grade I meningiomas who had undergone resective surgery over the past 20 years was retrospectively reviewed. Simpson and Shinshu grading scales were used to evaluate the extent of resection. Statistical analysis was conducted using Kaplan-Meier curves and Cox proportionalhazards regression.

RESULTS Four hundred fifty-eight patients were eligible for analysis. Overall tumor recurrence rates for Simpson resection Grades I, II, III, and IV were 5\%,22\%, 31\%, and 35\%, respectively. After Cox regression analysis, Simpson Grade I (extensive resection) was revealed as a significant predictor of RFS $(p=0.003)$. Patients undergoing Simpson Grade I and II resections showed significant improvement in RFS compared with patients undergoing Grade III and IV resections $(p=0.005)$. Extent of resection had a significant effect on recurrence rates for both skull base $(p=0.047)$ and convexity $(p=0.012)$ meningiomas. Female sex and a Karnofsky Performance Scale score $>70$ were also identified as independent predictors of RFS after resection of WHO Grade I meningioma.

CONCLUSIONS In this patient cohort, a significant association was noted between extent of resection and rates of tumor recurrence. In the authors' experience the Simpson grading system maintains its relevance and prognostic value and can serve an important role for patient education. Even though complete tumor resection is the goal, surgery should be tailored to each patient according to the risks and surgical morbidity.

http://thejns.org/doi/abs/10.3171/2016.1.JNS151842

KEY WORDS WHO grade; meningioma; Simpson grade; recurrence; oncology

$\mathrm{M}$ ENINGIOMAS represent $13 \%-26 \%$ of all intracranial tumors, and $90 \%$ of them are benign WHO Grade I tumors. ${ }^{26}$ According to the 2000 and 2007 WHO grading criteria, meningiomas are classified into 3 groups: Grade I (benign tumor), Grade II (atypical meningiomas), and Grade III (anaplastic or malignant meningiomas). ${ }^{26}$ Many neurosurgeons prefer complete microsurgical removal as treatment for meningiomas when feasible and with acceptable clinical risk. However, these tumors can recur even after complete resection. ${ }^{17,37}$ More- over, they can recur even after substantial time from the primary surgery has passed. Consider, for example, that Simpson noted in his seminal article a recurrence after 13.5 years. ${ }^{33}$ Various predictors such as extent of resection, tumor pathological characteristics, tumor location and size, tumor extension along different vital brain structures, and patient age and sex can affect the recurrence rates of meningiomas. ${ }^{37}$ In 1957 Simpson suggested that aggressive resection of meningiomas (the entire tumor along with adjacent bone and dura mater) is associated with lower rates 
of subsequent recurrence. ${ }^{33}$ However, the importance of the Simpson grading system in predicting recurrence after the resection of meningiomas has been questioned several times since its original description..$^{33}$ The authors of a recent study have argued that aggressive meningioma resection did not result in a significant reduction of recurrence rates as compared with rates following resection of only the tumor itself or when leaving a small residual tumor attached to vital structures in the brain..$^{34}$ Advances in resection techniques, instrumentation, and microscope technology have improved the success rate of resection and lowered complication rates..$^{30}$ In our study we sought to evaluate the relevance of the Simpson grading system in predicting recurrence rates after the resection of WHO Grade I meningiomas by reviewing our experience with patients who underwent resection and were followed up at our institution.

\section{Methods}

We performed this study after obtaining approval from the institutional review board at the LSU Health Sciences Center, Shreveport, Louisiana. Information related to clinical history, neuroimaging, surgical technique, and outcomes in patients with meningiomas who had undergone resection between January 1995 and December 2014 was collected retrospectively by review of the medical record and relevant imaging.

Central pathology review was done to classify WHO Grade I meningiomas on the basis of the listed criteria. ${ }^{20}$ We reevaluated the cases diagnosed before 2007 and reclassified them according to the latest WHO grading system. The extent of resection was assessed using the Simpson (Supplemental Table 1) ${ }^{33}$ and modified Shinshu grading scales (Supplemental Table 2). ${ }^{1}$ The latter grading system, while infrequently used in the literature, aims to assess the extent of meningioma resection and involves more subclassifications of resection. The Simpson grading system is largely based on macroscopic resection criteria, while the modified Shinshu grading system also includes assessment of surgical removal at the microscopic level.

Gross-total resection followed by a good functional outcome is expected in most patients with meningioma. Therefore, we compared Simpson Grades I and II (complete resection) to Simpson Grades III and IV (subtotal resection).

Follow-up data were collected from the study population. Neuroimaging studies were performed at 6-month intervals during the 1st year after resection and annually thereafter.

\section{Statistical Analysis}

The statistical analysis was conducted using SPSS software version 21.0 (IBM Corp.). Kaplan-Meier analysis was used to assess RFS. The log-rank (Mantel-Cox) test was used to assess significance in recurrence rates. A univariate and multivariate Cox proportional-hazards regression model was used to determine independent significant factors of RFS. Chi-square tests were also used where appropriate. A $\mathrm{p}$ value $<0.05$ was considered significant.

\section{Results}

\section{Characteristics of Patients and Tumors}

A total of 525 patients underwent resection of meningioma between 1995 and 2014. After initial screening, 458 patients who had undergone resection of WHO Grade I meningiomas were eligible for evaluation (Table 1). One hundred twenty-seven patients $(27.7 \%)$ were male, and $331(72.3 \%)$ were female. Two hundred ninety-six patients $(64.5 \%)$ were white, and 146 (31.8\%) were African American. The median patient age was 56 years (range 13-98 years). Three hundred eighteen tumors $(69.4 \%)$ were located along the skull base, $102(22.2 \%)$ arose from the convexity, and $32(7 \%)$ arose from the falx or tentorium (Table 2 and Fig. 1). Each case was graded according to its extent of resection. Eighty cases (17.5\%) underwent Simpson Grade I resection; 294 cases (64.2\%), Grade II resection; 32 cases (7\%), Grade III resection; and 52 cases (11.4\%), Grade IV resection.

One hundred twenty-eight patients $(28 \%)$ were lost to follow-up (Table 3). Two hundred sixty-one patients (79\%) remained recurrence free during the follow-up period, and 69 patients $(21 \%)$ experienced tumor recurrence. The average duration of follow-up was 54 months (1-250 months).

\section{Recurrence-Free Survival Outcome}

The median recurrence-free survival (RFS) period among all 330 patients was 128 months. RFS rates at 3, 5 , and 10 years after resection were $90 \%, 78 \%$, and $60 \%$, respectively. The recurrence rates varied at different time points in the entire follow-up period, as shown in Fig. 2. The recurrence rate was higher and earlier in Grade III (31\%) and Grade IV (35\%) resections, followed by Grade II $(22 \%)$ and Grade I (5\%).

TABLE 1. Summary of characteristics in 458 patients with meningioma who underwent resection

\begin{tabular}{cc}
\hline \multicolumn{1}{c}{ Variable } & No. $(\%)$ \\
\hline Age in yrs & 56 \\
\hline Median & $13-98$ \\
\hline Range & $127(27.7)$ \\
\hline Sex (\%) & $331(72.3)$ \\
\hline Male & \\
\hline Female & $296(64.6)$ \\
\hline Ethnicity & $146(31.9)$ \\
\hline White & $16(3.5)$ \\
\hline African American & \\
\hline Other & $289(63)$ \\
\hline Clinical feature & $50(11)$ \\
\hline Headache & $70(15.3)$ \\
\hline Confusion & $25(5.4)$ \\
\hline Vision impairment & $41(9.0)$ \\
\hline Seizure & $14(3.0)$ \\
\hline Gait disturbance & \\
\hline Forgetfulness & $2(0.4)$ \\
\hline Associated disorder &
\end{tabular}


TABLE 2. Summary of WHO Grade I meningioma characteristics

\begin{tabular}{|c|c|}
\hline Variable & No. $(\%)$ \\
\hline \multicolumn{2}{|l|}{ Tumor location } \\
\hline Skull base & $318(69.4)$ \\
\hline Anterior fossa & $177(38.6)$ \\
\hline Olfactory groove & $35(7.6)$ \\
\hline Clinoidal & $20(4.4)$ \\
\hline Tuberculum & $17(3.7)$ \\
\hline Diaphragmatic & $7(1.5)$ \\
\hline Sphenoid wing & $80(17.5)$ \\
\hline Other & $18(3.9)$ \\
\hline Middle fossa & $50(11)$ \\
\hline Posterior fossa & $91(19.9)$ \\
\hline CPA & $41(9.0)$ \\
\hline Petroclival & $45(9.8)$ \\
\hline Other & $5(1.1)$ \\
\hline Convexity & $102(22.3)$ \\
\hline Frontal & $46(10)$ \\
\hline Parietal & $30(6.5)$ \\
\hline Temporal & $10(2.2)$ \\
\hline Occipital & $14(3.1)$ \\
\hline Cerebellum & $2(0.4)$ \\
\hline Falx \& tentorium & $32(7)$ \\
\hline Other & $6(1.3)$ \\
\hline \multicolumn{2}{|l|}{ Simpson grade } \\
\hline I & $80(17.5)$ \\
\hline II & $294(64.2)$ \\
\hline III & $32(7)$ \\
\hline IV & $52(11.4)$ \\
\hline \multicolumn{2}{|l|}{ Modified Shinshu grade } \\
\hline 1 & $73(16)$ \\
\hline II & $311(68)$ \\
\hline III & $21(4.6)$ \\
\hline IV & $53(11.6)$ \\
\hline
\end{tabular}

$\mathrm{CPA}=$ cerebellopontine angle.

\section{Simpson Grading for 330 Cases}

The median RFS time for Simpson Grades I, II, III, and IV was $247,116,68$, and 85 months, respectively. The difference in the median RFS reached statistical significance $(\mathrm{p}=0.001, \log$-rank test; Fig. 3A). When data for patients undergoing resection Grades I and II were combined and compared with data for patients who underwent resection Grades III and IV, the median RFS time was 133 and 85 months, respectively ( $p=0.004$, log-rank test; Fig. 3B).

\section{Modified Shinshu Grading for 330 Cases}

The median RFS time for Shinshu Grades I, II, III, and IV was $248,128,69$, and 86 months, respectively. The difference in median survival reached statistical significance $(\mathrm{p}=0.002$, log-rank test; Fig. 3C). When data for patients undergoing resection Grades I and II were combined and compared with those for patients who underwent resec- tion Grades III and IV, the median RFS was 134 and 86 months, respectively ( $\mathrm{p}=0.009$, log-rank test; Fig. 3D).

\section{Simpson Grading of Skull Base Meningioma Resections}

The median RFS for Simpson Grades I, II, III, and IV was $248,114,102$, and 85 months, respectively. The difference in median survival reached statistical significance ( $p=0.047, \log$-rank test; Fig. 4A). When data for patients undergoing resection Grades I and II were combined and compared with those for patients who underwent resection Grades III and IV, the median RFS time was 129 and 85 months, respectively ( $p=0.045$, log-rank test; Fig. 4B).

\section{Modified Shinshu Grading of Skull Base Meningioma Resections}

The median RFS for Shinshu Grades I, II, III, and IV was $247,117,95$, and 85 months, respectively. The difference in median survival reached statistical significance $(p$ $=0.03$, log-rank test; Fig. 4C). In addition, when combined data for patients undergoing resection Grades I and II were compared with those for patients who underwent resection Grades III and IV, the median RFS time was 134 and 86 months, respectively ( $p=0.07$, log-rank test; Fig. 4D).

\section{Simpson Grading of Convexity Meningioma Resections}

The median RFS for Simpson Grades I, II, III, and IV was $152,98,8$, and 67 months, respectively. The difference in median survival reached statistical significance $(\mathrm{p}$ $<0.0001$, log-rank test; Fig. 5A). When data for patients undergoing resection Grades I and II were combined and compared with those for patients who underwent resection Grades III and IV, the median RFS time was 128 and 65 months, respectively ( $p=0.004$, log-rank test; Fig. 5B).

\section{Modified Shinshu Grading of Convexity Meningioma Resections}

The median RFS for Shinshu Grades I, II, III, and IV was $129,105,11$, and 67 months respectively. The difference in median survival reached statistical significance $(\mathrm{p}$ $<0.0001$, log-rank test; Fig. 5C). In addition, when data for Shinshu Grades I and II were combined and compared with data for Grades III and IV, the median RFS time was 128 and 65 months, respectively. The difference in median survival reached statistical significance $(p=0.003$, log-rank test; Fig. 5D).

\section{Patient Sex}

The median RFS was 79 months for the male patients and 139 months for the female patients. This difference in median survival time between the 2 groups reached statistical significance ( $p=0.015, \log$-rank test). This difference in recurrence rates according to patient sex was also observed for patients who underwent resection of convexity tumors ( $p=0.001$ ), but was not significant for patients who underwent resection of skull base meningioma $(p=0.14$; Supplemental Fig. 1).

\section{Ethnicity}

The median RFS was 116 months for whites and 109 months for African Americans. The difference between the 2 groups did not reach statistical significance $(p=0.47$, log-rank test). 


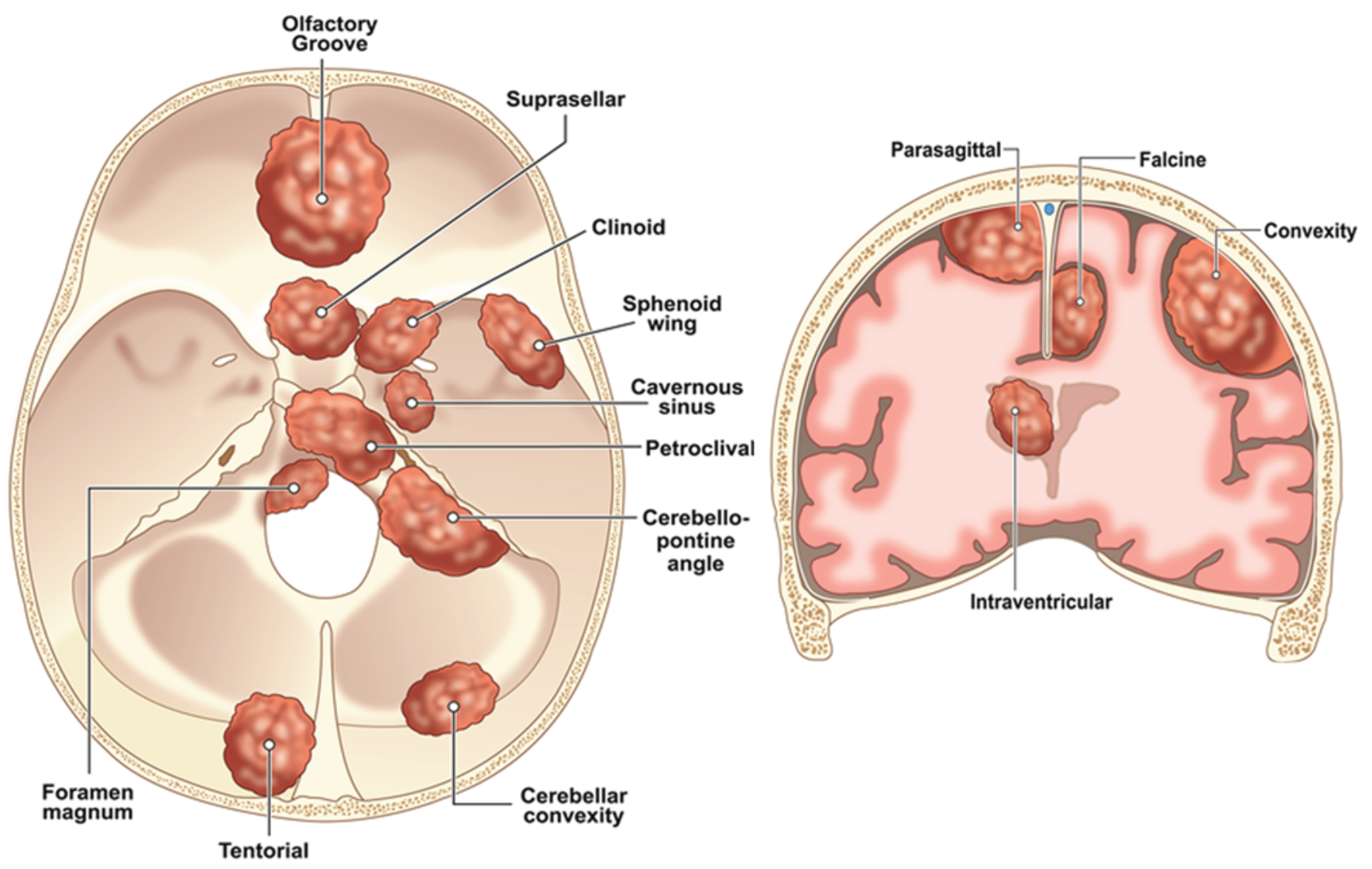

FIG. 1. Illustrations showing locations of intracranial meningiomas. Left: Skull base locations of tumors. Right: Convexity, parasagittal, falcine, and intraventricular locations of tumors. Copyright LSU Health Sciences Center. Published with permission.

Patient Age

The median RFS for patients aged $>65$ years was 122 months. For patients aged 65 years and younger, median survival time was 126 months. This difference in median survival time between the 2 groups did not reach statistical significance $(\mathrm{p}=0.34, \log$-rank test $)$

\section{KPS Score}

The median RFS time for patients with a Karnofsky Performance Scale (KPS) score > 70 was 159 months. For patients with a KPS score $\leq 70$, median RFS was 110 months. This difference in median survival time between the 2 groups reached statistical significance $(p=0.03$, logrank test; Supplemental Fig. 2).

\section{Complications}

Symptomatic improvement and complications are shown in Tables 4 and 5. Postoperative complications occurred in 11 patients $(3.3 \%)$ who developed postsurgical infection, 13 patients (3.9\%) who experienced new hydrocephalus, 4 patients $(1.2 \%)$ who developed deep vein thrombosis, 2 patients $(0.6 \%)$ who developed cerebrospinal fluid leakage, and 1 patient $(0.3 \%)$ each who experienced pulmonary embolism, pneumonia, and renal failure. Fifty-two patients $(16 \%)$ required further treatment with repeat resection, and 26 cases $(8 \%)$ underwent further treatment with stereotactic radiosurgery (Gamma Knife) after the initial resection.
TABLE 3. Demographics for 128 patients lost to follow-up*

\begin{tabular}{cc}
\hline Variable & No. \\
\hline Age in yrs & 56 \\
\hline Median & $13-93$ \\
\hline Range & $37(8)$ \\
\hline Sex & $91(20)$ \\
\hline Male & \\
\hline Female & $79(17.2)$ \\
\hline Ethnicity & $40(8.7)$ \\
\hline White & $9(2)$ \\
\hline African American & $85(18.5)$ \\
\hline Other & $34(7.4)$ \\
\hline Location of tumor & $6(1.3)$ \\
\hline Skull base & $3(0.06)$ \\
\hline Convexity & \\
\hline Falx \& tentorium & $33(7.2)$ \\
\hline Other & $79(17.2)$ \\
\hline Simpson grade & $5(1.1)$ \\
\hline I & $11(2.4)$ \\
\hline II &
\end{tabular}

* Percentages based on 458 patients. 


\section{G I-IV}

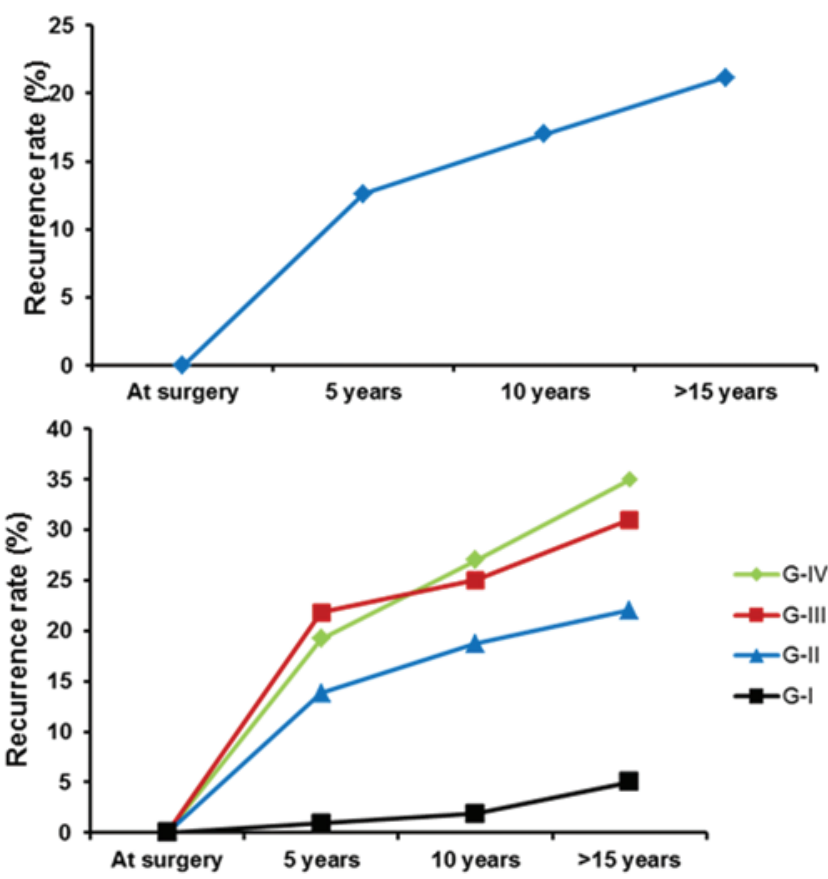

FIG. 2. Upper: Overall recurrence rate at different time points in the study period. Lower: Recurrence rate at different time points based on Simpson grade of resection in all patients with WHO Grade I meningioma. G I-IV = Grade I-IV.

\section{Predictive Factors of Survival}

Univariate and multivariate Cox regression analysis was performed to identify predictors of RFS for patients with WHO Grade I meningiomas (Table 6). The following covariates were included in the models: sex (male vs female), race (white vs African American), age (> 65 vs $\leq$ 65 years), location (convexity, skull base), Simpson Grades I and II vs Grades III and IV, Shinshu Grades I and II vs Grades III and IV, and KPS score (> 70 vs $\leq 70)$. In the univariate analysis, Simpson Grades I and II $(\mathrm{p}=0.005)$, Shinshu Grades I and II $(p=0.01)$, KPS score $>70(p=$ $0.03)$, and female sex $(\mathrm{p}=0.016)$ were identified as positive predictors of RFS for all cases. However, in the multivariate analysis, only Simpson Grade I $(p=0.02)$ and KPS

\section{TABLE 4. Summary of follow-up results in 330 patients}

\begin{tabular}{lc}
\hline \multicolumn{1}{c}{ Parameter } & No. (\%) \\
\hline Total no. of patients w/ follow-up & $330(72)$ \\
\hline Patients w/ no recurrence & $261(79)$ \\
\hline Patients w/ recurrence & $69(21)$ \\
\hline Further treatment after initial resection & $52(16)$ \\
\hline Craniotomy & $26(8)$ \\
\hline GKRS & $13(3.9)$ \\
\hline VP shunt & \\
\hline Median time to further treatment in mos (range) & $33(2-169)$ \\
\hline Craniotomy & $22(3-183)$ \\
\hline GKRS
\end{tabular}

GKRS = Gamma Knife radiosurgery; VP = ventriculoperitoneal.
TABLE 5. Symptomatic improvement and complications*

\begin{tabular}{lccc}
\hline \multicolumn{1}{c}{ Clinical Feature } & Preop $\dagger$ & Postop $\ddagger$ & p Value \\
\hline Symptom & & & \\
\hline Headache & $289(63)$ & $56(16.9)$ & $\mathbf{0 . 0 0 0 1}$ \\
\hline Vision impairment & $70(15.3)$ & $17(5)$ & $\mathbf{0 . 0 3 1}$ \\
\hline Confusion & $50(11)$ & $10(3)$ & $\mathbf{0 . 0 4 8}$ \\
\hline Ataxia & $41(9.0)$ & $6(1.8)$ & $\mathbf{0 . 0 1 8}$ \\
\hline Weakness \& numbness & $36(7.9)$ & $0(0)$ & $\mathbf{0 . 0 0 6}$ \\
\hline Seizure & $25(5.4)$ & $15(4.5)$ & 1.0 \\
\hline Dizziness & $17(3.7)$ & $12(3.6)$ & 1.00 \\
\hline Dementia & $14(3.1)$ & $0(0)$ & 0.24 \\
\hline Hearing deficit & $7(1.5)$ & $0(0)$ & 0.49 \\
\hline Complication & & \\
\hline Deep vein thrombosis & & $11(3.3)$ \\
\hline Infection & $1(0.3)$ \\
\hline Pneumonia & $1(0.3)$ \\
\hline Pulmonary embolism & $1(0.3)$ \\
\hline Renal failure & $2(0.6)$ \\
\hline CSF leakage & $13(3.9)$ \\
\hline New hydrocephalus \\
\hline * Boldface type indicates statistical significance. \\
$\begin{array}{l}\text { Percentages based on 458 patients. } \\
\text { Percentages based on 330 patients since 128 patients were lost to follow-up. }\end{array}$
\end{tabular}

score $>70(p=0.02)$ were identified as positive predictors of RFS for all cases. In the the skull base group, Simpson Grades I and II ( $p=0.047)$ were identified as positive predictors of RFS on univariate analysis, but Shinshu Grades I and II did not reach statistical significance $(\mathrm{p}=0.08)$. In the the convexity meningioma cohort, Simpson Grades I and II $(\mathrm{p}=0.012)$ and Shinshu Grades I and II $(\mathrm{p}=0.011)$ were identified as positive predictors of RFS on univariate analysis. Age $(\mathrm{p}=0.38)$ and race $(\mathrm{p}=0.73)$ did not show any significant association with RFS in this study.

\section{Discussion}

Although the majority of meningiomas are benign in nature, recurrence depends on the resection grade. Recurrence rates for meningiomas after resection vary among studies and range between $15 \%$ and $25 \%$. As expected, the amount of residual tumor has a significant effect on meningioma recurrence rates. Simpson demonstrated this idea by defining the extent of microsurgical resection in 5 established grades of resection ${ }^{33}$ This grading system led to the conclusion that a "cure" for meningiomas could be achieved by gross-total resection, including wide resection of the attached dura and underlying bone. ${ }^{11,13,24}$ Similarly, the extent of resection has been quite persistently identified as a predictor of recurrence in previous studies of WHO Grade I meningiomas., ${ }^{5,13,24}$ A Simpson Grade I resection can most often be achieved when the meningioma is located along the convexity; however, resection becomes challenging or impossible in cases of parasagittal meningiomas infiltrating the sinus or invasive skull base meningiomas in difficult-to-access locations (for example, petroclival). In those cases complete surgical removal can 

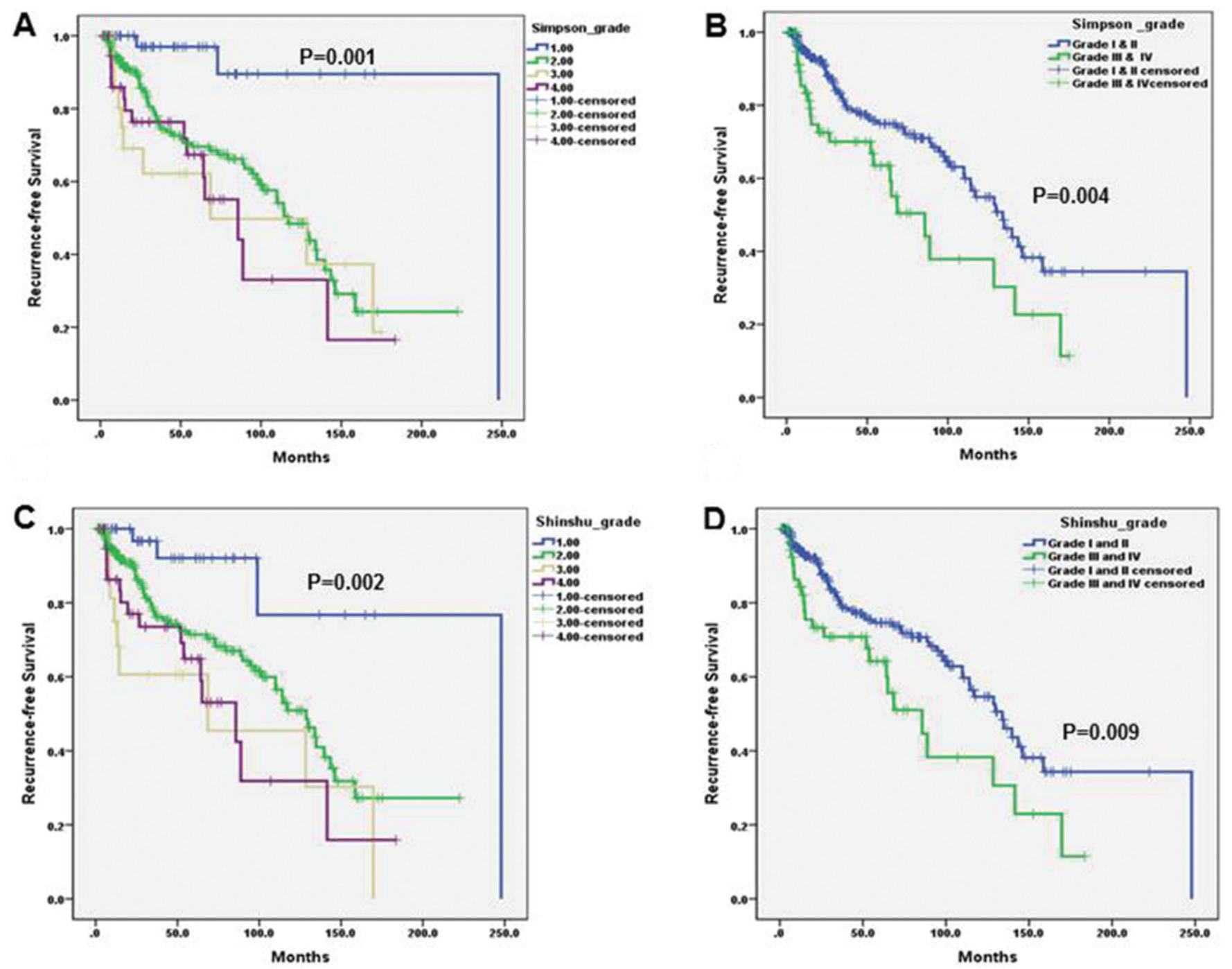

FIG. 3. A: Comparison of RFS according to Simpson grade of resection in all patients with WHO Grade I meningiomas. B: Comparison of RFS according to Simpson grade (I and II vs III and IV) of resection in all patients with WHO Grade I meningiomas. C: Comparison of RFS according to Shinshu grading system of resection in all patients with WHO Grade I meningiomas. D: Comparison of RFS according to Shinshu grade (I and II vs III and IV) of resection in all cases with WHO Grade I meningiomas. $p<0.05$ was considered significant. Figure is available in color online only.

carry a high risk of severe postoperative morbidity. Over the years a paradigm shift has occurred among neurosurgeons, who opt for a safer degree of resection that minimizes risks to the patient's postoperative functional status at the cost of leaving small amounts of residual tumor that can be treated with imaging surveillance or adjuvant treatment via stereotactic radiosurgery.

We reviewed our experience in the management of 458 patients with WHO Grade I meningiomas surgically treated over a 20-year period. Overall recurrence rates in the original Simpson paper ${ }^{33}$ were $9 \%$ for Grade I resection, $16 \%$ for Grade II, $29 \%$ for Grade III, 39\% for Grade IV, and $100 \%$ for Grade V. In our study here the overall rate of recurrence was $21 \%$, and it was significantly associated with extent of resection $(p=0.001)$. The overall recurrence rates were 5\% for Simpson Grade I, 22\% for Grade II, $31 \%$ for Grade III, and 35\% for Grade IV. Similar recurrence rates were noted in previously published studies as well. ${ }^{3,12} \mathrm{We}$ observed a similar trend in recurrence rates in our study when the Shinshu grading system $(\mathrm{p}=0.002)$ of resection was used. Recent studies, including our own, have revealed that tumor control rates have not deviated significantly from those reported in Simpson's original publication despite recent improvements in our ability to detect smaller tumor remnants.

However, Sughrue and colleagues have challenged the relevance of the Simpson resection grading system as a predictor of the recurrence of WHO Grade I meningiomas. ${ }^{34}$ These authors found only a negligible benefit in aggressive attempts to resect meningiomas with their attached dura and underlying bone, compared with removing the entire tumor alone or leaving a small residual tumor. Although Sughrue et al. partially agreed with the general consensus of complete removal for convexity meningiomas, they did not support complete removal for skull base meningiomas. On the contrary, other recent series by Hasseleid et al. ${ }^{9}$ and 

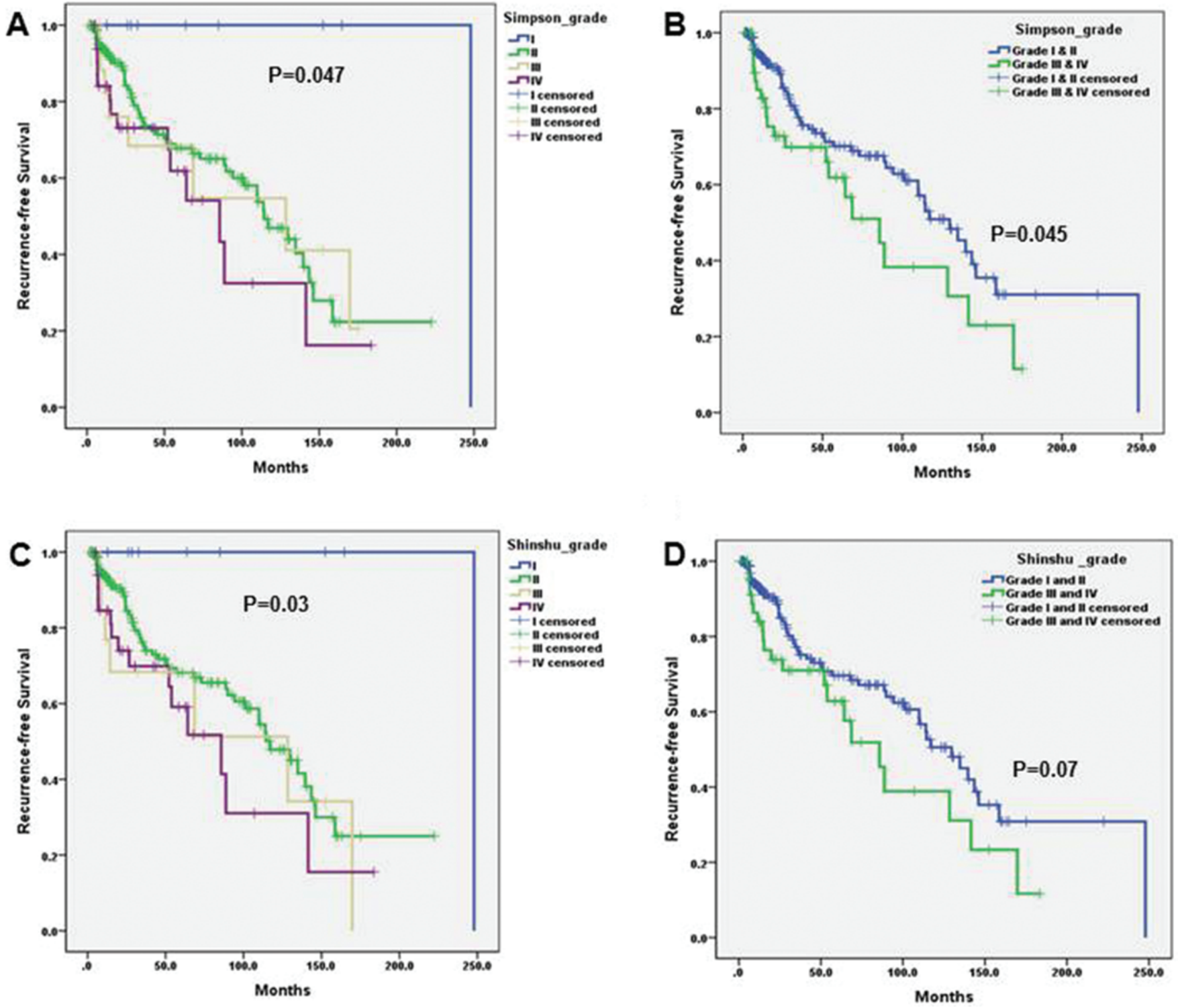

FIG. 4. A: Comparison of RFS according to Simpson grades of resection for skull base meningiomas. B: Comparison of RFS according to Simpson grades (I and II vs III and IV) of resection for skull base meningiomas. C: Comparison of RFS according to Shinshu grading system of resection for skull base meningiomas. D: Comparison of RFS according to Shinshu grading system of resection (I and II vs III and IV) for skull base meningiomas. $p<0.05$ is considered as significant. Figure is available in color online only.

van Alkemade et al., ${ }^{36}$ along with older reports, ${ }^{5,13,24}$ have strongly supported a significant association between Simpson grades and recurrence rates of benign meningiomas including skull base meningiomas. Similarly, our results support Simpson's concept of resection, and they contradict the findings of Sughrue and colleagues. Hasseleid et al. ${ }^{9}$ explained that Sughrue's conclusions were based on a group that was too small (77 convexity lesions) for their findings to be transferable. Our results agree with the findings of Hasseleid et al. (391 convexity lesions). In our series, convexity (102 lesions) and skull base (318 lesions) meningiomas showed a strong correlation with Simpson resection grade, recurrence rate, and RFS. However, meningiomas in falcine and tentorial regions did not show a correlation with resection grade or tumor recurrence, and that may be due to a low volume of cases (32 lesions) in those regions. In addition, in Sughrue's series, $30 \%$ of patients underwent Grade IV resection, whereas only $11 \%$ of cases in our study underwent Grade IV resection. This may have played a role in the contradiction of each other's results. van Alkemade et al. ${ }^{36}$ showed that older patients (age $>65$ years) usually underwent less radical surgery and experienced worse overall survival. Therefore, van Alkemade et al. ${ }^{36}$ suggested that Sughrue's work could be explained by patient selection and confounding competing risk factors. In the series by Sughrue et al., ${ }^{34} 71.3 \%$ of the cases underwent preoperative embolization. These authors suggested that the tumor control rate was worse in patients who underwent Grade IV resection without preoperative embolization. This result indicates minor beneficial effect 

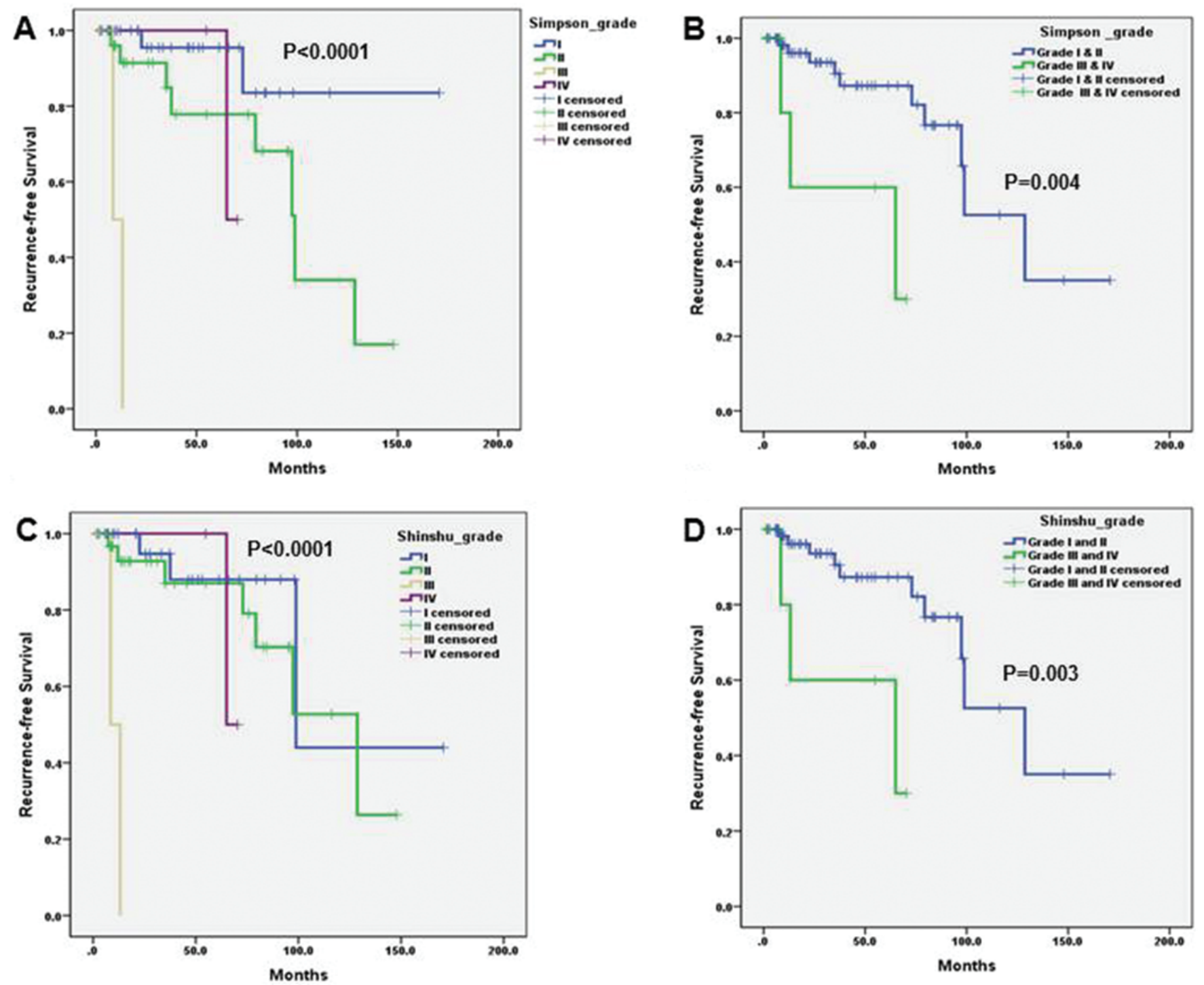

FIG. 5. A: Comparison of RFS according to Simpson grades of resection for convexity meningiomas. B: Comparison of RFS according to Simpson grades (I and II vs III and IV) of resection for convexity meningiomas. C: Comparison of RFS according to Shinshu grading system of resection for convexity meningiomas. D: Comparison of RFS according to Shinshu grading system of resection (I and II vs III and IV) for convexity meningiomas. $p<0.05$ is considered as significant. Figure is available in color online only.

of preoperative embolization in their series. In contrast, in our study not a single patient underwent preoperative embolization. This may be one of the reasons for the differing results in the resection rate. Regardless, the beneficial role of preoperative embolization is controversial and not the topic of this paper. ${ }^{28,32}$ Lastly, Sughrue et al. claimed that their results could be due to advances in imaging, surgical techniques, and histopathological grading of tumors in the last few decades. However, the findings of recent studies, including the present one, still validate the general consensus of a correlation between Simpson grade of resection and tumor recurrence.

\section{Convexity Tumors and Recurrence After Resection}

The ability to achieve a Simpson Grade I resection is affected by tumor location. It is easier to achieve a more extensive resection of convexity meningiomas, and it has been proposed that a true Simpson Grade I resection is possible only in this tumor group. ${ }^{25,27}$ This proposal has been confirmed by several large series.9,36 In addition, Kinjo et al ${ }^{16}$ has even described a Grade 0 (removal of an additional dural margin of about $2 \mathrm{~cm}$ around the tumor) excision for convexity meningiomas to further minimize the possibility of recurrence. In our study, recurrence rates of WHO Grade I convexity meningiomas after complete resection remained quite small (0.4\%). In addition, a strong correlation between Simpson grade and RFS was observed. This result was consistent with a previous report that demonstrated $0 \%$ recurrence rate after complete resection of benign meningiomas. ${ }^{27}$ Similarly, when using the modified Shinshu grading system, the recurrence rates of WHO Grade I convexity meningiomas were also small 
TABLE 6. Cox regression analysis for prognostic factors*

\begin{tabular}{|c|c|c|c|c|}
\hline \multirow[b]{2}{*}{ Variable } & \multicolumn{2}{|c|}{ Univariate } & \multicolumn{2}{|c|}{ Multivariate } \\
\hline & $\mathrm{HR}(95 \% \mathrm{Cl})$ & $p$ Value & $\mathrm{HR}(95 \% \mathrm{Cl})$ & p Value \\
\hline Age, $>65$ yrs (vs $\leq 65$ yrs) & $0.79(0.47-1.33)$ & 0.38 & $1.17(0.68-2.02$ & 0.56 \\
\hline Sex, female (vs male) & $0.63(0.38-0.91)$ & 0.016 & $1.28(0.81-2.03)$ & 0.28 \\
\hline Ethnicity, white (vs African American) & $0.94(0.66-1.34)$ & 0.73 & $2.77(0.67-11.5)$ & 0.16 \\
\hline \multicolumn{5}{|l|}{ Simpson grade } \\
\hline \multicolumn{5}{|l|}{ Overall cases } \\
\hline Grade I vs II-IV & $0.12(0.03-0.48)$ & 0.003 & $0.09(0.01-0.68)$ & 0.02 \\
\hline Grade I \& II vs III \& IV & $0.52(0.32-0.82)$ & 0.005 & $0.91(0.29-2.85)$ & 0.87 \\
\hline \multicolumn{5}{|l|}{ Skull base meningioma } \\
\hline Grade I \& II vs III \& IV & $0.60(0.36-0.99)$ & 0.047 & & \\
\hline \multicolumn{5}{|l|}{ Convexity meningioma } \\
\hline Grade I \& II vs III \& IV & $0.16(0.04-0.67)$ & 0.012 & & \\
\hline \multicolumn{5}{|l|}{ Shinshu grading } \\
\hline \multicolumn{5}{|l|}{ Overall cases } \\
\hline Grade I vs II-IV & $5.0(1.6-16.04)$ & 0.006 & $1.35(0.27-7.27)$ & 0.72 \\
\hline Grade I \& II vs III \& IV & $1.86(1.16-2.98)$ & 0.010 & $0.70(0.23-2.14)$ & 0.53 \\
\hline \multicolumn{5}{|l|}{ Skull base meningioma } \\
\hline Grade I \& II vs III \& IV & $1.57(0.95-2.62)$ & 0.08 & & \\
\hline \multicolumn{5}{|l|}{ Convexity meningioma } \\
\hline Grade I \& II vs III \& IV & $6.42(1.53-26.88)$ & 0.011 & & \\
\hline KPS score, $>70$ vs $\leq 70$ & $1.78(1.05-3.04)$ & 0.03 & $1.92(1.11-3.31)$ & 0.019 \\
\hline
\end{tabular}

* Boldface type indicates statistical significance.

$(0.6 \%)$, and again there was a strong correlation between complete resection and RFS.

\section{Skull Base Meningiomas and Recurrence Rates After Resection}

Determining the appropriate treatment strategy for skull base meningiomas can represent a formidable challenge. ${ }^{8,23}$ Given their nature, location, and proximity to major neurovascular structures, skull base meningiomas are more difficult to resect completely. Most surgeons often prefer a conservative approach that avoids extensive repair of the cranial base after the resection of skull base dura to minimize the risks of a cerebrospinal fluid leakage. ${ }^{7}$ As with meningiomas in other regions of the brain, the recurrence of skull base meningiomas has been associated with extent of resection..$^{10,19,31}$ In our study we confirmed an association between the extent of resection (using the Simpson or Shinshu systems) and RFS. However, this association is sometimes unpredictable in meningiomas in certain skull base locations, particularly for sphenopetroclival or cavernous meningiomas. ${ }^{6,35}$

Since the original Simpson publication, additional factors have been investigated as regards their association with meningioma recurrence rates.,16,18,21 Residual neoplastic cells around the craniotomy site or meningoepithelial cells along the dural tail can cause a recurrence. ${ }^{3,21}$ One study demonstrated an association between peritumoral edema and meningioma recurrence. ${ }^{21}$ Other studies have revealed that neovascularization and cell proliferation are associated with meningioma recurrence. ${ }^{3,18}$ A negative as- sociation has been described between rates of RFS and an advanced age and a lower KPS score. The negative impact of older age on survival, surgical mortality, and morbidity is well established, and perhaps the association between an advanced age and lower rates of RFS can be explained by the fact that extensive resection is discouraged in elderly patients. ${ }^{4,22}$ In our cohort an advanced age was not significantly associated $(p=0.38)$ with RFS. Male patients demonstrated higher rates of recurrence after resection, an observation that has been described in a previous report as well. ${ }^{15}$ Similarly patients with KPS scores lower than 70 had increased rates of recurrence, and KPS score has been previously described as a predictor of meningioma recurrence after resection. ${ }^{2,14,31}$

\section{Study Limitations}

The present study has several limitations inherent to its retrospective nature. Our series contains meningiomas located at different locations with perhaps varying patterns of growth; however, a subgroup analysis was performed to address this problem. Another issue is the fact that the resections were performed by multiple surgeons with different levels of surgical expertise. The proportion of patients with skull base meningiomas was large in our cohort, a factor that may be explained by the practice patterns of the principal author. Furthermore, the study extends over more than 15 years and $28 \%$ of patients were lost to followup, which may affect the observed outcomes. Such a long follow-up period was necessary, however, given the nature of these tumors and their often slow rates of growth. 


\section{Conclusions}

The significance of the Simpson resection grading system and its correlation with RFS has been well established. Results from our present cohort verify the system's validity and use including in cases of skull base meningiomas. In our experience, the Simpson grading system maintains its relevance and prognostic value and can serve an important role for patient education. Even though complete tumor resection is the goal, resection should be tailored to each patient depending on the risks and surgical morbidity.

\section{Acknowledgments}

We thank Mr. David W. Wright (computer graphics designer, Medical Communications, LSU Health Shreveport) for kindly providing the illustration (Fig. 1) in our paper.

\section{References}

1. Almefty R, Dunn IF, Pravdenkova S, Abolfotoh M, Al-Mefty $\mathrm{O}$ : True petroclival meningiomas: results of surgical management. J Neurosurg 120:40-51, 2014

2. Alvernia JE, Dang ND, Sindou MP: Convexity meningiomas: study of recurrence factors with special emphasis on the cleavage plane in a series of 100 consecutive patients. J Neurosurg 115:491-498, 2011

3. Ayerbe J, Lobato RD, de la Cruz J, Alday R, Rivas JJ, Gómez $\mathrm{PA}$, et al: Risk factors predicting recurrence in patients operated on for intracranial meningioma. A multivariate analysis. Acta Neurochir (Wien) 141:921-932, 1999

4. Bateman BT, Pile-Spellman J, Gutin PH, Berman MF: Meningioma resection in the elderly: nationwide inpatient sample, 1998-2002. Neurosurgery 57:866-872, 2005

5. Beks JW, de Windt HL: The recurrence of supratentorial meningiomas after surgery. Acta Neurochir (Wien) 95:3-5, 1988

6. Couldwell WT, Fukushima T, Giannotta SL, Weiss MH: Petroclival meningiomas: surgical experience in 109 cases. J Neurosurg 84:20-28, 1996

7. Couldwell WT, Heros R, Dolenc V: Editorial. Skull base meningiomas. Neurosurg Focus 30(5):Introduction, 2011

8. Hashimoto N, Rabo CS, Okita Y, Kinoshita M, Kagawa N, Fujimoto Y, et al: Slower growth of skull base meningiomas compared with non-skull base meningiomas based on volumetric and biological studies. J Neurosurg 116:574-580, 2012

9. Hasseleid BF, Meling TR, Rønning P, Scheie D, Helseth E: Surgery for convexity meningioma: Simpson Grade I resection as the goal: clinical article. J Neurosurg 117:999-1006, 2012

10. Ichinose $\mathrm{T}$, Goto $\mathrm{T}$, Ishibashi $\mathrm{K}$, Takami $\mathrm{T}$, Ohata $\mathrm{K}$ : The role of radical microsurgical resection in multimodal treatment for skull base meningioma. J Neurosurg 113:1072-1078, 2010

11. Jääskeläinen J: Seemingly complete removal of histologically benign intracranial meningioma: late recurrence rate and factors predicting recurrence in 657 patients. A multivariate analysis. Surg Neurol 26:461-469, 1986

12. Jääskeläinen J, Haltia M, Servo A: Atypical and anaplastic meningiomas: radiology, surgery, radiotherapy, and outcome. Surg Neurol 25:233-242, 1986

13. Jellinger K, Slowik F: Histological subtypes and prognostic problems in meningiomas. J Neurol 208:279-298, 1975

14. Jung MH, Moon KS, Lee KH, Jang WY, Jung TY, Jung S: Surgical experience of infratentorial meningiomas: clinical series at a single institution during the 20 -year period. J Korean Neurosurg Soc 55:321-330, 2014
15. Kajiwara K, Fudaba H, Tsuha M, Ueda H, Mitani T, Nishizaki T, et al: [Analysis of recurrences of meningiomas following neurosurgical resection.] No Shinkei Geka 17:1125-1131, 1989 (Jpn)

16. Kinjo T, al-Mefty O, Kanaan I: Grade zero removal of supratentorial convexity meningiomas. Neurosurgery 33:394399, 1993

17. Klinger DR, Lewis JJ, Hatanpaa K, Choe K, Mickey B, Barnett S: Atypical meningiomas: recurrence, re-operation and radiotherapy. World Neurosurg 84:839-845, 2015

18. Lee KS, Hoshino T, Rodriguez LA, Bederson J, Davis RL, Wilson CB: Bromodeoxyuridine labeling study of intracranial meningiomas: proliferative potential and recurrence. Acta Neuropathol 80:311-317, 1990

19. Liu J, Chakrabarti I, Mcdermott MW: (2014-11-16 17:21:40 UTC) Resection of bilateral C1 neurofibromas using a unilateral modified far-lateral approach. Cureus 6:e227, 2014

20. Louis DN, Ohgaki H, Wiestler OD, Cavenee WK, Burger PC, Jouvet A, et al: The 2007 WHO classification of tumours of the central nervous system. Acta Neuropathol 114:97-109, 2007

21. Mantle RE, Lach B, Delgado MR, Baeesa S, Bélanger G: Predicting the probability of meningioma recurrence based on the quantity of peritumoral brain edema on computerized tomography scanning. J Neurosurg 91:375-383, 1999

22. McCarthy BJ, Davis FG, Freels S, Surawicz TS, Damek DM, Grutsch J, et al: Factors associated with survival in patients with meningioma. J Neurosurg 88:831-839, 1998

23. McGovern SL, Aldape KD, Munsell MF, Mahajan A, DeMonte F, Woo SY: A comparison of World Health Organization tumor grades at recurrence in patients with non-skull base and skull base meningiomas. J Neurosurg 112:925933, 2010

24. Melamed S, Sahar A, Beller AJ: The recurrence of intracranial meningiomas. Neurochirurgia (Stuttg) 22:47-51, 1979

25. Mirimanoff RO, Dosoretz DE, Linggood RM, Ojemann RG, Martuza RL: Meningioma: analysis of recurrence and progression following neurosurgical resection. J Neurosurg 62:18-24, 1985

26. Modha A, Gutin PH: Diagnosis and treatment of atypical and anaplastic meningiomas: a review. Neurosurgery 57:538550, 2005

27. Morokoff AP, Zauberman J, Black PM: Surgery for convexity meningiomas. Neurosurgery 63:427-434, 2008

28. Oka H, Kurata A, Kawano N, Saegusa H, Kobayashi I, Ohmomo T, et al: Preoperative superselective embolization of skull-base meningiomas: indications and limitations. J Neurooncol 40:67-71, 1998

29. Samii M, Klekamp J, Carvalho G: Surgical results for meningiomas of the craniocervical junction. Neurosurgery 39:1086-1095, 1996

30. Sanai N, Sughrue ME, Shangari G, Chung K, Berger MS, McDermott MW: Risk profile associated with convexity meningioma resection in the modern neurosurgical era. J Neurosurg 112:913-919, 2010

31. Scheitzach J, Schebesch KM, Brawanski A, Proescholdt MA: Skull base meningiomas: neurological outcome after microsurgical resection. J Neurooncol 116:381-386, 2014

32. Shah A, Choudhri O, Jung H, Li G: Preoperative endovascular embolization of meningiomas: update on therapeutic options. Neurosurg Focus 38(3):E7, 2015

33. Simpson D: The recurrence of intracranial meningiomas after surgical treatment. J Neurol Neurosurg Psychiatry 20:22-39, 1957

34. Sughrue ME, Kane AJ, Shangari G, Rutkowski MJ, McDermott MW, Berger MS, et al: The relevance of Simpson Grade I and II resection in modern neurosurgical treatment of World Health Organization Grade I meningiomas. J Neurosurg 113:1029-1035, 2010 
35. Talacchi A, Biroli A, Soda C, Masotto B, Bricolo A: Surgical management of ventral and ventrolateral foramen magnum meningiomas: report on a 64-case series and review of the literature. Neurosurg Rev 35:359-368, 2012

36. van Alkemade H, de Leau M, Dieleman EM, Kardaun JW, van Os R, Vandertop WP, et al: Impaired survival and longterm neurological problems in benign meningioma. Neuro Oncol 14:658-666, 2012

37. Yamasaki F, Yoshioka H, Hama S, Sugiyama K, Arita K, Kurisu K: Recurrence of meningiomas. Cancer 89:11021110,2000

\section{Disclosures}

The authors report no conflict of interest concerning the materials or methods in this study or the findings specified in this paper.

\section{Author Contributions}

Conception and design: Nanda, Bir, Maiti. Acquisition of data:
Bir. Analysis and interpretation of data: Bir, Maiti. Drafting the article: Bir. Critically revising the article: all authors. Reviewed submitted version of manuscript: all authors. Approved the final version of the manuscript on behalf of all authors: Nanda. Statistical analysis: Bir. Study supervision: Nanda.

\section{Supplemental Information}

Online-Only Content

Supplemental material is available with the online version of the article.

Supplemental Figures and Tables. http://thejns.org/doi/suppl/ 10.3171/2016.1.JNS151842.

\section{Correspondence}

Anil Nanda, Department of Neurosurgery, LSU Health Shreveport, 1501 Kings Hwy., Shreveport, LA 71103-3932. email: ananda@1suhsc.edu. 